\title{
Evaluation of the Layering of Rock Strata and Basement Rock Depth of a University Teaching Hospital Premises in Northern Nigeria
}

\author{
${ }^{* 1}$ INICHINBIA, S; ${ }^{2}$ SULE, PO \\ ${ }^{*}$ Department of Physics, University of Port Harcourt, Port Harcourt, Nigeria. \\ ${ }^{2}$ Department of Physics, Ahmadu Bello University, Zaria, Nigeria \\ *Corresponding author Email: Sonny.inichinbia@yahoo.com
}

\begin{abstract}
The layering of rock strata and depth to the basement rocks of a Federal University Teaching Hospital premises in Northern Nigeria was investigated in this study with the aim of providing 2D geo-electrical resistivity images of the subsurface for geotechnical development using a modern and state-of-the-art field instrument, the ABEM Automatic LUND Imaging System (Terrameter SAS 4000 and ES 464). Three profiles were covered and the data processed to display the variations of electrical resistivity using the RES2DINV software. The results of the survey in correlation with borehole data in the area revealed three distinct layers: the overburden which is about $16 \mathrm{~m}-26 \mathrm{~m}$ thick having a resistivity range of about $194 \Omega \mathrm{m}-1759 \Omega \mathrm{m}$. The weathered basement which is appreciably thick (about $5 \mathrm{~m}-14 \mathrm{~m}$ ), which is highly fractured and weathered, so constitutes a good aquifer having a resistivity range of about $0.687 \Omega \mathrm{m}-678 \Omega \mathrm{m}$ and the fresh crystalline basement having a resistivity of about $1223 \Omega \mathrm{m}$. The fresh crystalline rock is at variable depths of about $21 \mathrm{~m}-40 \mathrm{~m}$ below the surface.
\end{abstract}

DOI: https://dx.doi.org/10.4314/jasem.v22i4.28

Copyright: Copyright $\odot 2018$ Inichinbia and Sule. This is an open access article distributed under the Creative Commons Attribution License (CCL), which permits unrestricted use, distribution, and reproduction in any medium, provided the original work is properly cited.

Dates: Received: 07 January 2018; Revised: 22 February: 2018; Accepted: 16 March 2018

Keywords: Rock strata, Geotechnical, Electrical resistivity, Basement, Overburden

Pressure on natural resources from growing populations, with increasing demand for infrastructure and housing has increased over the past decades and can be expected to rise continually. Also, stress on the environment due to pollution has increased the need for detailed geological knowledge, for geotechnical development. Civil engineering studies are increasingly demanding more precise and more detailed geo-electrical information at shallow depth. Geo-electrical prospecting involves the detection of the surface effects produced by electrical current flow in the ground. Two dimensional (2D) resistivity prospecting yields information about both the lateral and vertical resistivity distribution of the earth subsurface. It can therefore, be used in a qualitative way for identification of structure and burial of depths of features at shallow depths.

Since electrical images provide a detailed 2D view of the subsurface structure, the present research study was designed to map a $2 \mathrm{D}$ geoelectrical resistivity image of the study area for geotechnical development. Using LUND automatic resistivity imaging system produced by $A B E M$ Instrument $A B$, the following objectives would be achieved: determination of the overburden thickness and the thickness of weathered basement. Also, we shall determine the overburden layering and estimate the depth to the basement.

Geo-electrical resistivity imaging has been used for "imaging fractures in hard rock terrain" by Barker (2001). 2D electrical resistivity surveying can form a powerful geological mapping tool for use in engineering and environmental applications, including hydrogeological mapping (Hassan et al., 1991 and Meads et al., 2003). In combination with a limited number of drilling reference points, with locations based on the resistivity results, reliable models of the subsurface can be created (Dahlin, 1996). This revealed that where fractures are present, the bedrock is expected to be more strongly weathered to a greater depth than where it is not fractured. A geophysical investigation of the groundwater potential in the Institute for Agricultural Research (IAR) farm, Samaru, using ABEM Terrameter SAS 300 revealed that most parts of the area have three subsurface layers while some parts have two subsurface layers. The topsoil is sandy, clayey, silty, lateritic top soil with fadama loam except the farm sites under cultivation which are sandy and fadama loam. The weathered basement has variable depth ranging from $1 \mathrm{~m}$ to about $16.6 \mathrm{~m}$. Thickness of the weathered basement ranges from about $3.4 \mathrm{~m}$ to about $38.2 \mathrm{~m}$. The fresh basement has a variable depth ranging from about $1.2 \mathrm{~m}$ to about 
$40 \mathrm{~m}$. Thus the aquifer lies partly in the top soil and partly in the weathered basement, the thickest portion of the aquifer coinciding with the thickest portion of the weathered basement (Umar, 2001). A resistivity survey in Jama'a village by Messrs Preussag Nigeria Limited with the aim of siting a borehole in the village has revealed the presence of faults within the bedrock, which have caused the down-throw of certain portions of the area (Umar, 2001). Therefore the objective of this paper is to evaluate the the Layering of Rock Strata and Basement Rock Depth of a University Teaching Hospital Premises in Northern Nigeria.

\section{MATERIALS AND METHODS}

The Survey Area: Shika is situated within the northern Nigerian Basement complex, (Figure 1). It lies between latitudes $11^{\circ} 70^{\prime} \mathrm{N}$ and $11^{\circ} 24^{\prime} \mathrm{N}$ and longitudes $07^{\circ} 31^{\prime} \mathrm{E}$ and $07^{\circ} 50^{\prime} \mathrm{E}$ within the Zaria sheet 102 . The mean elevation of the area is about 650 $\mathrm{m}-700 \mathrm{~m}$ above mean sea level. Ahmadu Bello University Teaching Hospital (ABUTH) is located in Shika, along Zaria-Funtua road north of Ahmadu Bello University (A.B.U.) main campus, Samaru, Zaria. It lies between latitudes $11.18^{\circ} \mathrm{N}$ and $11.17^{\circ} \mathrm{N}$ and longitudes $07.60^{\circ} \mathrm{E}$ and $07.61^{\circ} \mathrm{E}$. It is bordered by Zaria Academy in the north, Bomo village in the northeast, Area C, A.B.U. staff quarters, Institute for Agricultural Research (IAR) farm and its dam. Accessibility to the ABUTH is only by the ZariaFuntua road which is a prominent federal road. All season motorable roads, some of which are tarred exist within the premises. Figure 1 is a sketch of the Ahmadu Bello University Teaching Hospital (ABUTH), showing the investigated site.

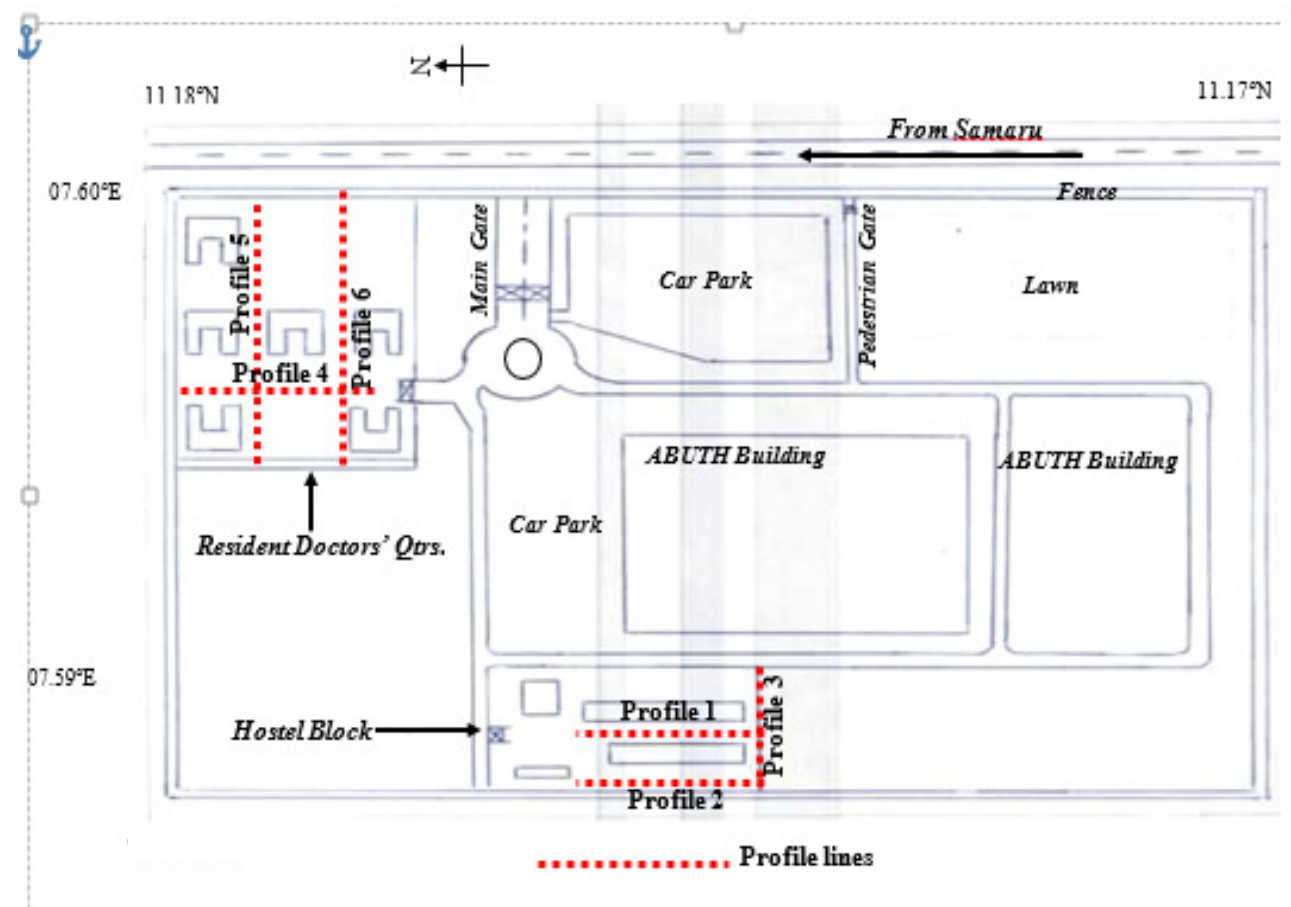

Fig 1. Layout of Experimental Profiles in the Survey Area

\section{GEOLOGY}

The Zaria crystalline rocks are part of the Nigerian Basement Complex, underlain by Precambrian rocks, so the geology of the area is the same as that of the Nigerian Basement complex. The rocks of the Basement complex occupy more than $50 \%$ of the total land surface of Nigeria, and accommodate the metasediments, which are made up of gneisses. Granitic intrusions form a suite of batholiths (the Zaria Batholiths), part of which outcrops as the Kufena Hill. The gneisses are found as small belts within the granite intrusions, and are also found east and west of the batholiths (Figure 2). The biotite gneiss extends westwards to form a gradational boundary with the schist belt (Wright and McCurry, 1970; McCurry, 1970 and McCurry, 1976).

Methods: A Wenner Continuous Vertical Electrical Sounding (CVES) array with protocol, WEN32SX was used to map the geo-electrical properties as an aid to characterizing the ground conditions. In the present survey, a $5 \mathrm{~m}$ interval between 41 electrodes was employed with each spread having a length of $200 \mathrm{~m}$. 
The survey data were processed to produce graphic depth sections of the thickness and resistivity of the subsurface electrical layers. The resistivity sections are correlated with ground interfaces such as soils and fill layers or soil-bedrock interfaces to provide engineers with detailed information on subsurface ground conditions (Batayneh, 2006).

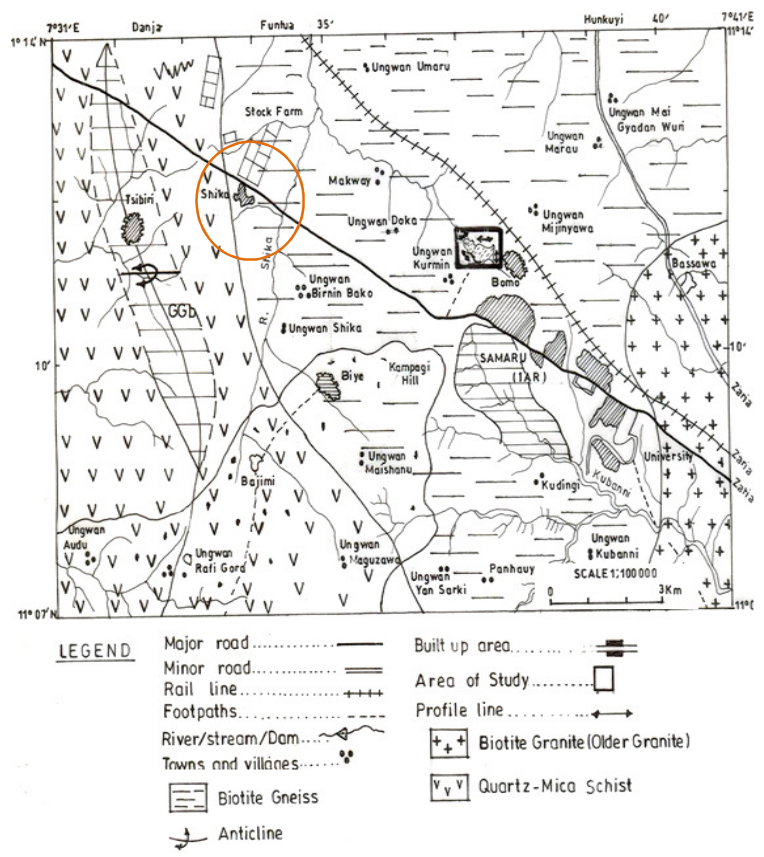

Fig 2. Geological map of Zaria Sheet 2.

Figure 3 shows schematically the current and potential distribution within a homogeneous isotropic ground in a vertical plane through the current electrodes $C_{1}$ and $\mathrm{C}_{2}$. When an external voltage is applied across them, there will be a flow of current through the earth from one electrode $C_{1}$ to the other, $C_{2}$. The resistivity method is based on measuring the potential between one electrode pair $\left(\mathrm{P}_{1}\right.$ and $\mathrm{P}_{2}$, called potential electrodes) while transmitting DC between another electrode pair $\left(\mathrm{C}_{1}\right.$ and $\left.\mathrm{C}_{2}\right)$ and $\mathrm{r}_{1}, \mathrm{r}_{2}, \mathrm{r}_{3}$ and $\mathrm{r}_{4}$ are the electrode separations. The rheostat varies the current I which is measured by the ammeter (A) while the voltmeter $(\mathrm{V})$ measures the potential difference $\Delta \mathrm{U}$.

The principle underlying the resistivity method is embodied in Ohm's law, which states that the current density at a given point is proportional to the electric field intensity at that point. Thus, Ohm's law gives the relationship between current density $\mathrm{J}$ (amperes $/ \mathrm{m}^{2}$ ) and electric field intensity $\mathrm{E}$ (in volts/m) as:

$\mathrm{J}=\sigma \mathrm{E}$

The symbol $\sigma$ is the conductivity of the medium. Also $\mathrm{E}$ is the gradient of a scalar potential $\mathrm{U}$ (in volts),

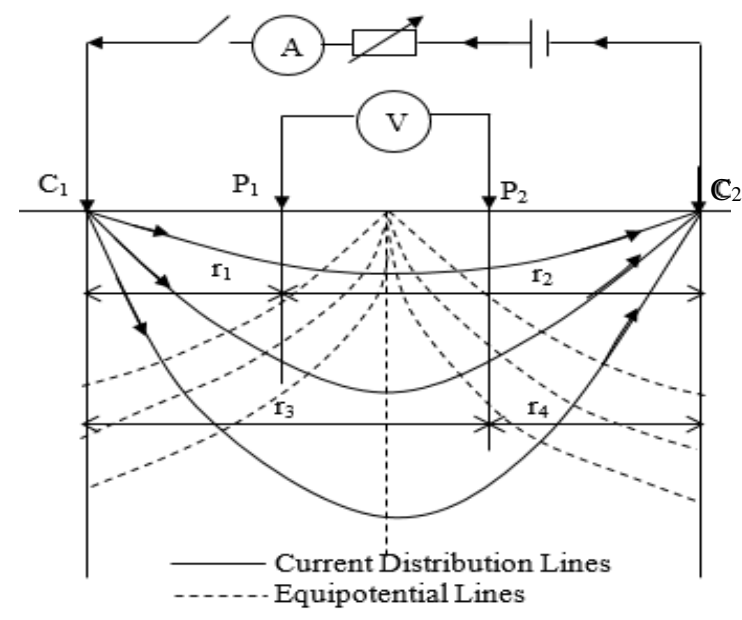

Fig 3. Current and potential distributions within homogeneous isotropic ground.

$E=-\nabla U$

Solving equation 2 further, gives

$\nabla^{2} \mathrm{U}=0$

Equation (3) is the so called Laplace's equation for a homogeneous earth. Thus, the potential difference between two arbitrarily located points on the surface of a homogeneous isotropic ground with two point current electrodes on the ground's surface is given by the expression.

$\Delta \mathrm{U}=\frac{I \rho}{2 \pi}\left(\frac{1}{r_{1}}-\frac{1}{r_{2}}-\frac{1}{r_{3}}+\frac{1}{r_{4}}\right)$

Where $r_{1}, r_{2}, r_{3}$, and $r_{4}$, are the electrode separations as shown in Figure 3. When the ground is not homogeneous $\rho$ becomes $\rho_{a}$ called the apparent resistivity and equation (4) can be written as:

$\rho_{a}=\frac{\Delta U}{I} \frac{2 \pi}{\left(\frac{1}{r_{1}}-\frac{1}{r_{2}}-\frac{1}{r_{3}}+\frac{1}{r_{4}}\right)}$

The result is independent of the positions of the electrodes and is not affected when the current electrodes and the potential electrodes are interchanged. The resistance $\mathrm{R}$ is calculated using Ohm's law:

$\mathrm{R}=\frac{\Delta U}{I}$ 
Where $\mathrm{R}$ is the resistance in ohms; $\Delta \mathrm{U}$ is the potential difference in volts; and $\mathrm{I}$ is the current in amperes.

The Wenner spread (WEN32SX) CVES is a robust array in the presence of measurement noise. It is well suited to resolving horizontal structures because it is more sensitive to vertical changes in resistivity than to horizontal changes in resistivity. It covers an intermediate depth range, has intermediate resolution and shows sensitivity to geological noise.

The LUND Resistivity imaging System consists of a basic unit, a standard resistivity meter (ABEM Terrameter SAS 4000), a (4x64) multi-channel relay matrix switch unit called Electrode Selector ES 464. The system also has four multi-conductor electrode cables wound on reels each with 21 take-outs, stainless steel electrodes and cable jumpers and various connectors. The system is compatible with a portable PC-type computer or note book (laptop). Operating power comes from an internal 12 volts rechargeable NiCd battery pack. Data acquisition software featuring automatic measuring process, in-field quality control of measurements, automatic roll along, electrode cable geometry and switching sequence defined in address and protocol files which allows user defined survey strategies and arrays, onscreen echo of measurement progress, software for graphical and depth interpretation including pseudo-section plotting in gray scale or colour, fully automatic 1-D Zohdy depth interpretation of Wenner CVES (ABEM instruction manual).

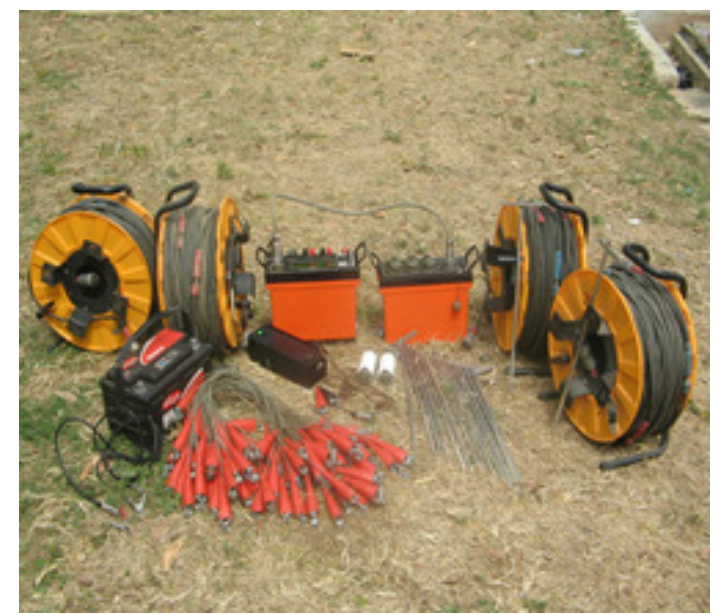

Fig 4. ABEM LUND Imaging System together with Terrameter SAS 4000 and ES 464 used for Electrical Resistivity Tomography

\section{RESULTS AND DISCUSSIONS}

The field data (pseudosections) are inverted to produce models representing subsurface electrical resistivity. In cases where resistivity contrast is gradual, smooth inversion is more suitable, while when there is a sharp variation in resistivity contrast, block inversion is preferable (Cardarelli and Fischanger, 2006). Interpreting the resistivity data consists of two steps: a physical interpretation of the measured data, resulting in a physical model, and a geological interpretation of the resulting physical parameters (Barker, 2001; Batayneh, 2006; Dahlin, 1996; Griffiths and Barker, 1993; Hassan, et al., 1991; Loke and Barker, 1996 and Griffiths et al., 1990). The large-scale VES data were interpreted with the state-of-the-art interpretation technique, called the 2D smoothed damped leastsquares inversion algorithm (Oldenburg and Li, 1999; Özürlan et al., 2006 and Olayinka and Barker, 1990.). The results obtained based on 2D inversion of field data and borehole information, were interpreted to determine the depth and extent of shallow bedrock, thickness of overburden, aquifer etc. Profiles 1 and 2 are north-south trending while a profile 3 is west-east trending. Profiles 1 and 2 are parallel to each other with profile 3 perpendicular to them. The profiles are indicated on the map of the study area (see Figure 1). The inversion result for each profile is shown in Figures 5 to 8 showing the images of the pseudosections (geo-electric sections) obtained from the processed data. The results show three distinct images for each profile. The upper image labelled (a) is a plot of the measured apparent resistivity pseudosection. The middle image labelled (b) is the calculated apparent resistivity pseudosection and the lower image labelled (c) is the true resistivity model obtained after a definite number of iterations of the inversion program. Borehole log is also superimposed on the inverse model for easy correlation

Figure 5 shows the resistivity inversion results (iteration 8, total average RMS error $10.2 \%$ ), for profile 1. Thus indicating that good fits between the measured (observed) and calculated apparent resistivity data were achieved. The robust data inversion option was used to remove the effect of a few data points that might be noisier in the inversion results and the robust model inversion option was also used. Apparent resistivity (in ohm-metre, $\Omega \mathrm{m}$ ) is plotted against pseudo-depth (Ps.Z, in metres, m), but with colour infill instead of line contours. A thick layer of very high resistivity (194 $\Omega \mathrm{m}-1223 \Omega \mathrm{m})$ is observed along the top of the resistivity image. This correlates with the observed dry and consolidated lateritic clay top soil with gravel and sand. This layer constitutes the overburden, which is about $10.8 \mathrm{~m}$ thick. The disintegrated schistose, sandy, silt, clay, and gravel channels that run through the cross-section correspond with the resistivity values $(30.8 \Omega \mathrm{m}-487$ $\Omega \mathrm{m})$. This is the fractured, saturated and highly weathered basement consisting of aquiferous sand and 
gravel. Here the aquifer is a low resistivity weathered material. Although fractures are not directly indicated, the increased thickness of weathering here provides a good reservoir. The zone of significantly lower resistivities $(<1.96 \Omega \mathrm{m}->12.3 \Omega \mathrm{m})$ in the inverse model indicates a zone of fracturing and weathering. This has a thickness of about $10 \mathrm{~m}$ at a depth of about $8 \mathrm{~m}$ from the surface and extends between the $80 \mathrm{~m}$ and $140 \mathrm{~m}$ marks. There is a high probability of bedrock fracturing. The depth to bedrock is greater than $30 \mathrm{~m}$. This pseudosection correlated well with the borehole logs obtained from the Preussag Ltd and ABUTH hostels.

Figure 6 shows the resistivity inversion results (iteration 9, total average RMS error $7.6 \%$ ), for profile 2. Thus indicating that good fits between the measured (observed) and calculated apparent resistivity data were achieved. Both the robust data inversion option and the robust model inversion options were used in the inversion of the data set. The top layer is composed of consolidated laterite, gravel, sand, silt and clay having a high resistivity range of $216 \Omega \mathrm{m}-684 \Omega \mathrm{m}$. This is the overburden or the first layer having a thickness of about $15 \mathrm{~m}$. Between $100 \mathrm{~m}$ and $130 \mathrm{~m}$ marks a high resistivity greater than $>2162 \Omega \mathrm{m}$ is observed in the overburden and its due to a dry, empty suck-away pit (septic tank) that was tiled. The weathered bedrock clearly shows on the image immediately underneath the overburden with a resistivity range of about $<21.7 \Omega \mathrm{m}->216 \Omega \mathrm{m}$. It is made up of gravel, sand and other weathered rock materials.

Between $120 \mathrm{~m}-160 \mathrm{~m}$ marks a low resistivity $(0.687$ $\Omega \mathrm{m}->6.86 \Omega \mathrm{m}$ ) section is observed to be at a depth of $21.7 \mathrm{~m}$ from the surface. This is probably a highly fractured and weathered zone containing clayey deposit trapped in the aquifer. Patches of high resistivity material are observed at $40 \mathrm{~m}, 70 \mathrm{~m}$ and 160 $\mathrm{m}$ marks and are probably a crystalline rock or possibly corestones or unweathered bedrock at depth less than $10 \mathrm{~m}$ from the surface. The basement is shown by the image, by the high resistivity of 2162 $\Omega \mathrm{m}$ and is believed to be at a depth greater than 21.7 $\mathrm{m}$. This suggests increased bedrock weathering and fracturing and possibly the presence of fractures in the bedrock. This Pseudosection correlated well with the borehole logs obtained from Shika main town.

Figure 7 shows the resistivity inversion results (iteration 5, total average RMS error 3.5\%), for profile 3 . Thus indicating that good fits between the measured (observed) and calculated apparent resistivity data were achieved. High resistivity $(815 \Omega \mathrm{m}->1408 \Omega \mathrm{m})$ weathered material of thickness less than $15.0 \mathrm{~m}$, which is composed of consolidated laterite, gravel, sand; clay and silt formed the overburden. Patches of unweathered bedrock ( $>2435 \Omega \mathrm{m}$ ), embedded in the consolidated laterite clearly shows below the $40 \mathrm{~m}, 90$ $\mathrm{m} 110 \mathrm{~m}$ and $170 \mathrm{~m}$ marks and are close to the surface, at a depth less than $10 \mathrm{~m}$.

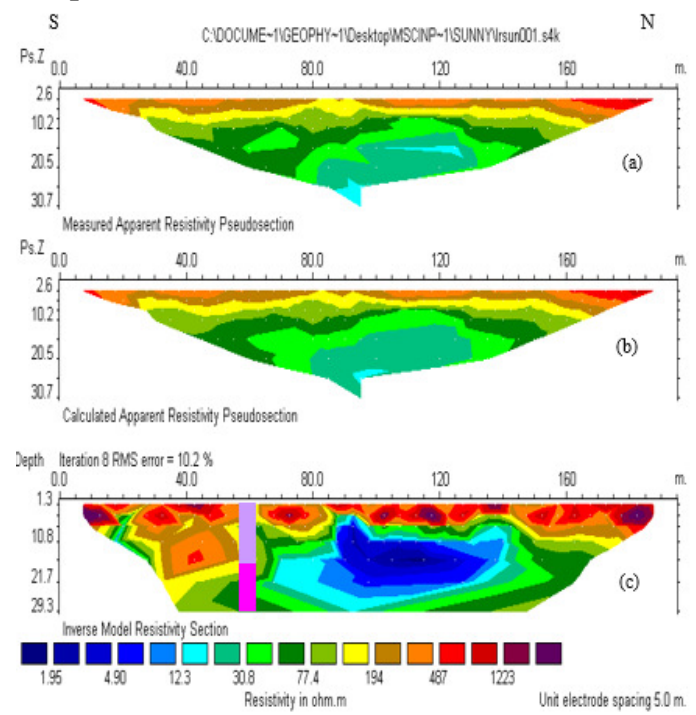

Fig 5. The result of $2 \mathrm{D}$ inversion of the Wenner-array data along survey line 1, in the ABUTH hostel: (a) is the observed data plotted as a Pseudosection; Ps. $Z$ = pseudo-depth. (b) is the calculated Pseudosection and $(c)$ is the inverse model showing true depth and true formation resistivity. The thin vertical section is a borehole log superimposed on the inverse model for easy correlation.

This layer overlay a low resistivity $(<158 \Omega \mathrm{m}->815$ $\Omega \mathrm{m}$ ) aquifer at a depth of about $15 \mathrm{~m}$ from the surface. This layer is composed of gravely sand and disintegrated schistose materials. There is a much lower resistivity $(52.8 \Omega \mathrm{m}-158 \Omega \mathrm{m})$ channel which is probably a fracture zone in the bedrock, and containing water. This is seen at a depth of about 21.7 $\mathrm{m}$ and rising to the surface below the $140 \mathrm{~m}$ mark. The increased thickness of weathering here provides a good reservoir with a higher probability of bedrock fracturing. The fresh basement is at a depth greater than $30 \mathrm{~m}$ as shown in the image. This pseudosection correlated well with the borehole logs obtained from the Preussag Ltd and ABUTH hostels. For each profile, the sand and gravel, and consolidated laterite top layer corresponded to a high resistivity, the basement and patches of it found in the sections corresponded to the highest resistivity, and the weathered basement with clay corresponded to the intermediate and lowest resistivity values. The low resistivity of the weathered basement is due to its water content. However, resistivity ranges are usually determined by superimposing the boreholes over the electrical resistivity image and observing the correlation between the borehole lithology and the image resistivity. 


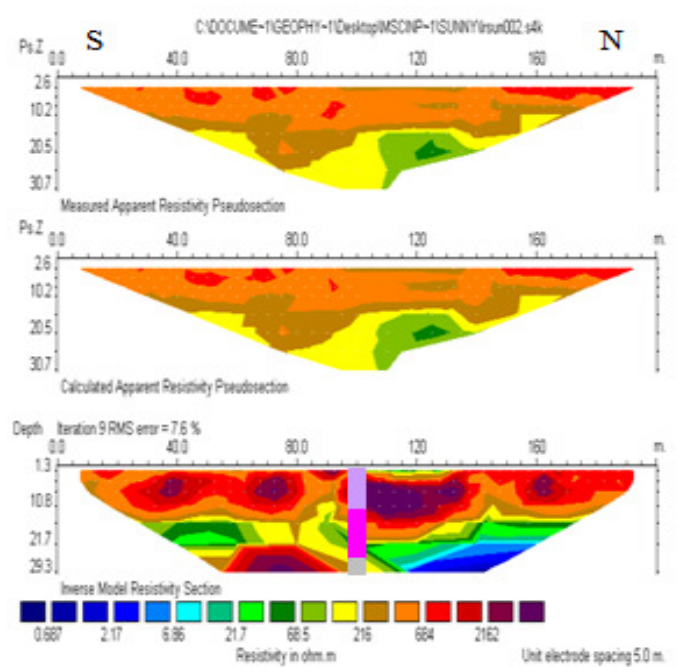

Fig 6. The result of $2 \mathrm{D}$ inversion of the Wenner-array data along survey line 2, in the ABUTH hostel.

However, correlation between the field results obtained shows that the overburden depth is the main factor controlling the electrical resistivity of the nearsurface material. Overburden is generally, though not always, more conductive than the underlying bedrock. This is due to the high porosity and, hence, higher water content, and to a generally higher content of electrically conductive clay minerals relative to the bedrock.

The 2D inversion results of the survey were correlated with the lithology information of boreholes obtained from the original hydrogeologic assessment report of the groundwater research department of the National Water Resources Institute (NWRI), Mando, Kaduna; Kaduna State, Nigeria. These boreholes are sited Jama'a village, and the hostels and the residential quarters of ABUTH.

The lithology obtained from the boreholes provided a good representation of the stratigraphic sequence of the area. Based on the electrical images obtained in the study area, three distinct layers were revealed.

(i) The Overburden: this is made up of two parts, the topmost of which is about $9 \mathrm{~m}$ thick and is composed of reddish brown lateritic clay.

The second part is about $7 \mathrm{~m}$ thick and is composed of brownish sandy clay. Combining these two parts together reveals an overburden with an average thickness of about $16 \mathrm{~m}-26 \mathrm{~m}$ which agrees with the borehole logs.

(ii) The Weathered Basement: the overburden is immediately underlain by the weathered basement which consists of disintegrated schistose rock materials, sand and gravel. This layer has a relatively low resistivity due to the presence of water and clay, which reduces the permeability.

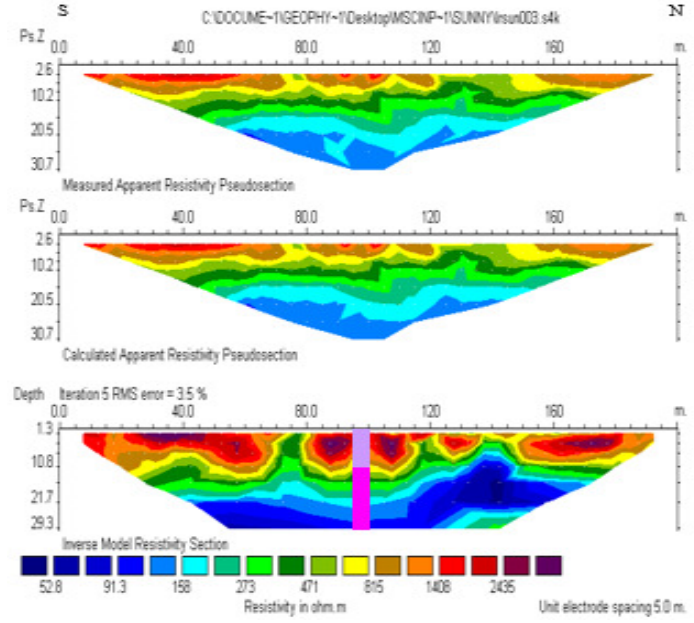

Fig 7. The result of $2 \mathrm{D}$ inversion of the Wenner-array data along survey line 3 , in the ABUTH hostel.

Thus this layer is regarded as the aquifer as it usually holds water. Also, the layer is highly weathered and the degree of weathering increases toward the southern part of the study area.

This increased thickness of bedrock weathering is a proof of the capability of this layer to provide a good reservoir with a higher probability of the presence of fractures in the basement. The average thickness of this layer is about $5 \mathrm{~m}-14 \mathrm{~m}$. Thus, this correlates well with the borehole logs of the site being investigated.

(iii) The Fresh Bedrock: the fresh basement rock was encountered at a variable depth of between $21 \mathrm{~m}$ and $>30 \mathrm{~m}$, in figure 4.3 and the rest of figures 4.4 to 4.7 respectively. The average depth of the fresh basement is about $40 \mathrm{~m}$ as provided by the borehole $\log$ (NWRI 1). The value of the resistivity of the basement rocks is appreciably high, rising from 1223 $\Omega \mathrm{m}$ up to $11918 \Omega \mathrm{m}$ which is indicative of typical crystalline bedrock. This layer is believed to grade indefinitely or infinitely downward. The average depth of penetration is about $29.3 \mathrm{~m}$. The basement though fresh, is frequently fractured which gives it a high permeability. But as fractures do not constitute a significant volume of the rock, fractured basement has low porosity.

Conclusions: Comparing RES2DINV resistivity values with the results of available logs of the boreholes in the survey area and its environs, it was found that the resistivity values correlates quite well with the geological formations revealed by the borehole logs. This then lend credence to the fact that electrical imaging is a powerful technique in the study of subsurface geology. This is because the electrical images provided detailed view of the subsurface structure thus, leading to a better understanding of the local geology and hydrogeology. Although 3D 
resistivity techniques are being developed rapidly, 2D surveying will probably in many applications remain the most useful for logistic and cost reasons. However, a number of $2 \mathrm{D}$ profiles can be combined to compile quasi 3D models.

Acknowledgements: The authors gratefully thank Prof. I. B. Osazuwa for his leadership as project leader of the AGRL, provision of financial and material support through the IPPS, Prof. Rabiu Nasiru, Ahmed Sadiq, Prof. K. M. Lawal, Joseph Osumeje, Bolaji T. Lawal, El-Khalil, postgraduate students of 2007/2008 session and many others whose names are not listed here and the staff of the Department of Physics, A. B. U., Zaria, for their invaluable contributions and support that has made this work a success.

\section{REFERENCES}

Barker, RD (2001). Imaging fractures in hardrock terrain. Research Note 2. University of Birmingham, UK. $1-4$.

Batayneh, AT (2006). Resistivity tomography as an aid to planning gas-pipeline construction, Risha area, north-east Jordan. Near Surface Geophysics, $4313-319$.

Cardarelli, E. and Fischanger, F. 2006. 2D data modelling by electrical resistivity tomography for complex subsurface geology. Geophysical Prospecting, $54121-133$.

Dahlin, $T$ (1996). 2D resistivity surveying for environmental and engineering applications. First Break 14 (7). 275 - 283.

Griffiths, D. H. and Barker, R. D. 1993. Twodimensional resistivity imaging and modeling in areas of complex geology. Journal of Applied Geophysics. 29, $211-226$.

Griffiths, DH; Turnbull, J; Olayinka, AI (1990). Twodimensional resistivity mapping with a computercontrolled array. First Break, 8 (40); 121 - 129.

Hassan, M; Ajayi, CO; Ojo, SB (1991). A Basement structure determined from Geoelectric mapping of the Kubanni River Basin, Zaria: Nigerian Journal of Physics, 3,166-173

Loke, MH; Barker, RO (1996). Rapid least-squares inversion of apparent resistivity pseudosections by a quasi-Newton method. Geophysical prospecting. 44:135-152.
McCury, P (1976). The geology of the Precambrian to Lower Paleozoic rocks of Northwestern Nigeria. A review in Kogbe, C.A. (Ed), Geology of Nigeria. Elizabethan Publishing Company, Lagos 15-39.

Meads, LN; Bently, LR; Mendoza, CA (2003). Application of electrical resistivity imaging to the development of a geologic model for a proposed Edmonton landfill site. Canadian Geotechnical Journal. 40, 551-558.

National Water Resources Institute (NWRI, 1). 2002. Groundwater Research Development. Completion Report. Borehole NR. GWR/HG05(1/6).

National Water Resources Institute (NWRI, 2). 2002. Groundwater Research Development. Completion Report. Borehole NR. HGD/IAR/01(1/6).

Olayinka, AI; Barker, R D (1990). Borehole siting in crystalline basement areas of Nigeria with a microprocessor-controlled Resistivity Traversing System. Ground Water. 28,178-183.

Oldenburg, DW; Li, Y (1999). Estimating depth of investigation in D.C. Resistivity and IP surveys. Geophysics. 64(2); 403-416.

Özürlan, G; Candansayar, ME; Şahin, M H (2006). Deep resistivity structure of the Dikili-Bergama region, west Anatolia, revealed by twodimensional inversion of vertical electrical sounding data. Geophysical Prospecting. 54,187 $-197$.

Umar, FA (2001). Geoelectric investigation of the groundwater potential in the Institute of Agricultural Research (IAR) farm, Samaru, Zaria. Unpublished M.Sc. thesis. Department of Physics, Ahmadu Bello University, Zaria.

Wright, JB; McCury, P (1970). The geology of Nigeria Sheet $102 \mathrm{SW}$, Zaria and its regions. Edited by M.J. Mooretimore. Department of Geography, Occasional Paper, No. 4, Ahmadu Bello University, Zaria. 